\title{
Veranstaltungskalender
}

\section{5| 2009}

Veranstaltungen Juni bis September

\begin{tabular}{|c|c|c|}
\hline Zeit und Ort & Thema der Veranstaltung & Veranstalter \\
\hline $\begin{array}{l}\text { 30. Juni - 03. Juli } 2009 \\
\text { in Karlsruhe }\end{array}$ & Information Security Management & $\begin{array}{l}\text { Secorvo Security Consulting GmbH } \\
\text { Ettlinger Straße 12-14, 76137 Karlsruhe } \\
\text { Tel.: 0721/255171-0; Fax: 0721/255171-100 } \\
\text { E-Mail: collage@secorvo.de }\end{array}$ \\
\hline $\begin{array}{l}\text { 07. - 10. Juli } 2009 \\
\text { in Karlsruhe }\end{array}$ & Forensik - Verfahren, Tools, Praxiserfahrung & $\begin{array}{l}\text { Secorvo Security Consulting GmbH } \\
\text { Ettlinger Straße 12-14, 76137 Karlsruhe } \\
\text { Tel.: 0721/255171-0; Fax: 0721/255171-100 } \\
\text { E-Mail: collage@secorvo.de }\end{array}$ \\
\hline $\begin{array}{l}\text { 13. - 17. Juli } 2009 \\
\text { in München }\end{array}$ & $\begin{array}{l}\text { ITSEC: IT-Netzsicherheit: Angriffsszenarien und Gegenmaßnah- } \\
\text { men (Anti-Hacking-Workshop) }\end{array}$ & $\begin{array}{l}\text { PROKODA GmbH } \\
\text { Stolberger Straße 309, } 50933 \text { Köln } \\
\text { Tel.: 0221/4854-0; Fax: 0221/4854-155 } \\
\text { E-Mail: info@prokoda.de }\end{array}$ \\
\hline $\begin{array}{l}\text { 16. Juli } 2009 \\
\text { in Darmstadt }\end{array}$ & SmartCards & $\begin{array}{l}\text { CAST e.V., } \\
\text { Fraunhoferstr. 5, 64283 Darmstadt } \\
\text { Tel.: 06151/155529; Fax: 06151/155499 }\end{array}$ \\
\hline $\begin{array}{l}\text { 22. - 24. Juli } 2009 \\
\text { in Berlin }\end{array}$ & IT-Grundschutz nach BSI: Erstellung eines Sicherheitskonzeptes & $\begin{array}{l}\text { SMLAN Softwaretraining } \\
\text { Kastanienallee 53, } 10119 \text { Berlin } \\
\text { Tel.: 030/4492545; Fax: 030/44340435 }\end{array}$ \\
\hline $\begin{array}{l}\text { 27. Juli } 2009 \\
\text { in Hamburg }\end{array}$ & IT-Sicherheit am Arbeitplatz - Awareness-Training & $\begin{array}{l}\text { CBT Training \& Consulting GmbH } \\
\text { Elektrastr. 6a, 81925 München } \\
\text { Tel.: 089/4576918-0; Fax: 089/4576918-25 } \\
\text { E-Mail: info@cbt-training.de }\end{array}$ \\
\hline $\begin{array}{l}\text { 07. - 11. September } 2009 \\
\text { In Karlsruhe }\end{array}$ & T.I.S.P. - Schulung & $\begin{array}{l}\text { Secorvo Security Consulting GmbH } \\
\text { Ettlinger Straße 12-14, 76137 Karlsruhe } \\
\text { Tel.: 0721/255171-0; Fax: 0721/255171-100 } \\
\text { E-Mail: collage@secorvo.de }\end{array}$ \\
\hline $\begin{array}{l}\text { 09. - 10. September } 2009 \\
\text { in Essen }\end{array}$ & IT-Trends Medizin / Health Telematics & $\begin{array}{l}\text { ZTG Zentrum für Telematik im Gesundheitswesen GmbH } \\
\text { Campus Fichtenhain 42, } 47807 \text { Krefeld } \\
\text { Tel.: 02151/82073-11/12; Fax: 02151/82073-30 }\end{array}$ \\
\hline $\begin{array}{l}\text { 14. - } 15 . \text { September } 2009 \\
\text { in Hamburg }\end{array}$ & Social Hacking / Geschäftsschädigende Handlungen & $\begin{array}{l}\text { IBS Schreiber GmbH } \\
\text { Zirkusweg 1, 20359 Hamburg } \\
\text { Tel.: 040/696985-15; Fax: 040/696985-31 } \\
\text { E-Mail: seminare@ibs-hamburg.com }\end{array}$ \\
\hline $\begin{array}{l}\text { 14. - 15. September } 2009 \\
\text { in Köln }\end{array}$ & Datenschutzpraxis im Unternehmen (Workshop) & $\begin{array}{l}\text { datakontext GmbH } \\
\text { Augustinusstr. 9d, 50226 Frechen } \\
\text { Tel.: 02243/065633; Fax: 02234/65635 } \\
\text { E-Mail: tagungen@datakontext.com }\end{array}$ \\
\hline $\begin{array}{l}\text { 17. - 18. September } 2009 \\
\text { in Darmstadt }\end{array}$ & BIOSIG 2009 & $\begin{array}{l}\text { CAST e.V., Claudia Prediger } \\
\text { Fraunhoferstr. 5, } 64283 \text { Darmstadt } \\
\text { Tel.: +49 } 6151155529 \\
\text { E-Mail: claudia.prediger cast-forum.de }\end{array}$ \\
\hline $\begin{array}{l}\text { 24. - 25. September } 2009 \\
\text { in Karlsruhe }\end{array}$ & $\begin{array}{l}\text { Datenschutzaudit: Best-Practice - Sinnvolle Planung und } \\
\text { Durchführung }\end{array}$ & $\begin{array}{l}\text { Secorvo Security Consulting GmbH } \\
\text { Ettlinger Straße 12-14, 76137 Karlsruhe } \\
\text { Tel.: 0721/255171-0; Fax: 0721/255171-100 } \\
\text { E-Mail: collage@secorvo.de }\end{array}$ \\
\hline
\end{tabular}

